\title{
Seasonal variation of thermal sensations in residential buildings in the hot summer and cold winter zone of China
}

Article

Accepted Version

Creative Commons: Attribution-Noncommercial-No Derivative Works 4.0

Liu, H., Wu, Y., Li, B., Cheng, Y. and Yao, R. (2017) Seasonal variation of thermal sensations in residential buildings in the hot summer and cold winter zone of China. Energy and Buildings, 140. pp. 9-18. ISSN 0378-7788 doi: https://doi.org/10.1016/j.enbuild.2017.01.066 Available at https://centaur.reading.ac.uk/68971/

It is advisable to refer to the publisher's version if you intend to cite from the work. See Guidance on citing.

Published version at: http://dx.doi.org/10.1016/j.enbuild.2017.01.066

To link to this article DOI: http://dx.doi.org/10.1016/j.enbuild.2017.01.066

Publisher: Elsevier

All outputs in CentAUR are protected by Intellectual Property Rights law, including copyright law. Copyright and IPR is retained by the creators or other copyright holders. Terms and conditions for use of this material are defined in the End User Agreement.

www.reading.ac.uk/centaur 
Central Archive at the University of Reading

Reading's research outputs online 


\title{
Seasonal variation of thermal sensations in residential buildings in the Hot Summer and Cold Winter Zone of China
}

\author{
Hong Liu ${ }^{1,2,3}$, Yuxin Wu ${ }^{1,2,3}$, Baizhan Li ${ }^{1,2,3}$, Yong Cheng ${ }^{1,2,3}$ and Runming Yao 1,2,4** \\ ${ }^{1}$ Joint International Research Laboratory of Green Buildings and Built Environments (Ministry of Education), \\ Chongqing University, Chongqing 400045, China \\ ${ }^{2}$ National Centre for International Research of Low-carbon and Green Buildings (Ministry of Science and \\ Technology), Chongqing University, Chongqing 400045, China \\ ${ }^{3}$ Key Laboratory of Three Gorges Reservoir Region's Eco-Environment (Ministry of Education), Chongqing \\ University, Chongqing 400045, China \\ ${ }^{4}$ School of the Built Environment, University of Reading, Reading RG6 6AW, UK \\ *Corresponding author: Hong Liu, Tel: +86 2365127353, Email address: liuhong1865@163.com \\ ** Corresponding author: Runming Yao, Tel: +44 1183788606, Email address: r.yao@ reading.ac.uk
}

\begin{abstract}
The seasonal differences of neutral or acceptable temperatures between summer and winter were revealed by previous researchers, but the studies on the difference of human thermal adaption in transitional seasons are insufficient. To clarify this, this paper analyzes the data from a nationwide field study database, including a year-long survey which was carried out in 505 residential buildings in six cities located in the Hot Summer and Cold Winter (HSCW) zone of China involving 11,524 subjects. Results show a significant difference of adaptive responses in different seasons. Air temperature is found to be the most significant driver for behavioral responses, and a lag of behavioral responses behind climate change in transitional seasons is observed. Occupants not only adjust clothing insulation according to air temperature in different seasons, but also actively control indoor air movement, including closing/opening windows and using fans. The seasonal, monthly and daily
\end{abstract}


neutral temperatures are studied, implying that occupants' thermal experience history has significant effect on their thermal comfort by behavioral, physiological and psychological paths. Thus, the running mean air temperature method and aPMV model are recommended for thermal comfort evaluation in free-running space. The research results provide comprehensive understanding of the thermal comfort demand which directly affects the energy needs for heating and cooling purpose. The findings provide scientific evidence to the concept that dynamic thermal comfort temperature range should be considered in the evaluation of indoor thermal environment.

Keywords: Seasonal variation; Thermal sensation; Dynamic thermal environment; Behaviors; Neutral temperature; Adaptive thermal comfort

Nomenclature

\begin{tabular}{|c|c|}
\hline PMV & Predicted Mean Vote \\
\hline TSV & Thermal Sensation Vote \\
\hline AMV & Actual Mean Vote (of thermal sensation) \\
\hline aPMV & adaptive model of PMV \\
\hline ePMV & extended model of PMV \\
\hline MTU & Monthly Temperature Up (winter $\rightarrow$ spring $\rightarrow$ summer) \\
\hline MTD & Monthly Temperature Down (summer $\rightarrow$ autumn $\rightarrow$ winter) \\
\hline $\mathrm{V}_{\mathrm{a}}$ & indoor air velocity, $\mathrm{m} / \mathrm{s}$ \\
\hline $\mathrm{V}_{\text {out }}$ & outdoor air velocity, $\mathrm{m} / \mathrm{s}$ \\
\hline $\mathrm{RH}_{\mathrm{a}}$ & indoor relative humidity, $\%$ \\
\hline $\mathrm{RH}_{\text {out }}$ & outdoor relative humidity, $\%$ \\
\hline $\mathrm{T}_{\mathrm{a}}$ & indoor air temperature, ${ }^{\circ} \mathrm{C}$ \\
\hline $\mathrm{T}_{\text {out }}$ & outdoor air temperature, ${ }^{\circ} \mathrm{C}$ \\
\hline $\mathrm{T}_{\text {out, } \mathrm{m}}$ & monthly mean outdoor air temperature, ${ }^{\circ} \mathrm{C}$ \\
\hline $\mathrm{T}_{\mathrm{n}}$ & neutral temperature, ${ }^{\circ} \mathrm{C}$ \\
\hline
\end{tabular}




\begin{tabular}{|l|l|}
\hline$T_{n, s}$ & seasonal neutral temperature, ${ }^{\circ} \mathrm{C}$ \\
\hline$T_{n, m}$ & monthly neutral temperature, ${ }^{\circ} \mathrm{C}$ \\
\hline$T_{n, d}$ & daily neutral temperature, ${ }^{\circ} \mathrm{C}$ \\
\hline$T_{\text {od-i }}$ & the $24-h$ daily mean temperatures of i days ago, ${ }^{\circ} \mathrm{C}$ \\
\hline AC & Air-conditioned \\
\hline NV & Naturally Ventilated \\
\hline SD & Standard Deviation \\
\hline $\mathrm{HSCW}$ & Hot Summer and Cold Winter \\
\hline $\mathrm{P}$ & Probability \\
\hline $\mathrm{R}^{2}$ & determination coefficient \\
\hline $\mathrm{I}_{\mathrm{cl}}$ & ensemble clothing insulation \\
\hline $\mathrm{PFU}$ & Proportion of Fan Use \\
\hline $\mathrm{PWO}$ & Proportion of Windows Opened \\
\hline $\mathrm{N}$ & Number of samples \\
\hline
\end{tabular}

\section{Introduction}

The existing building stock in cities in China's Hot Summer and Cold Winter (HSCW) climate zone covers some 9 billion $\mathrm{m}^{2}$ of which residential buildings accounted for $66 \%$ in 2012 [1] . The HSCW zone has unique climate characteristics, i.e. hot long summers, cold wet winters, a rainy climate with monsoon, and so on, as described in reference [2]. Due to economic growth, there has been a continued and growing demand for the improvement of the indoor thermal environment and consequently the growth of energy demand for both heating and cooling $[1,3]$. Such situations have a considerable adverse impact on the nation's energy reduction target [4].

In residential buildings, besides the building design [5], occupants' behavioral habits, varieties of thermal sensation and comfort requirements [6] significantly impact on energy consumption. There would be a potential waste of energy [7] to maintain the indoor thermal environment within the thermal 
comfort thresholds using the thermal comfort standards if there is not a full understanding of the different thermal sensation characteristics in different seasons in free-running buildings. Our previous study in naturally ventilated classrooms demonstrates that occupants' thermal sensations dynamically respond to the outdoor climate [8]. Because of adaptions to the natural climate using available facilities, occupants have a wider acceptable temperature range in NV (Naturally ventilated) buildings than that in AC (Air-conditioned) buildings [9-11]. Many studies [12-20] also conclude that differences exist in occupants' thermal sensations between summer and winter, due to the obvious differences in outdoor climates between these two seasons.

China has a diverse climate and consequently is divided into five climate zones for building thermal design purposes [21]. Among the five zones, the HSCW zone has unique climatic characteristics and the residents have diverse adaptations for ensuring thermal comfort [22-26] in freerunning space. This has attracted many scholars to engage in this research. Some previous studies were concentrated in a specific city for year-long study [26-27], whilst some studies focused on a specific season (e.g. summer) in this area [28-29]. However, most studies [30-33] were only conducted during a specific season in one city/province.

The aim of this study is to obtain a sophisticated understanding of residents' thermal sensations and their dynamic responses to the variation in outdoor climates for different seasons in free-running space. This will provide a fundamental knowledge of the thermal comfort demand for residential buildings in this region. Consequently, a dynamic solution to achieve indoor thermal comfort in residential buildings will possibly be developed to meet the requirements for both thermal comfort and energy efficiency.

\section{Methods}

Onsite field measurements and a questionnaire survey have been conducted in this research. Statistical regression methods are used for the analysis of data. 


\subsection{Brief of the field study}

A large-scale, nationwide, thermal comfort survey was conducted in the five climate zones of China during the period 2008-2011 [34]. The field study in each city lasted for more than twelve months. The data were collected in daytime from 8:30 to 20:30 by visiting selected typical buildings in a city on three to five occasions in each month. During the field study, thermal comfort questionnaire surveys were conducted, while the indoor and outdoor thermal environmental parameters, such as air temperature, relative humidity, and air velocity were measured.

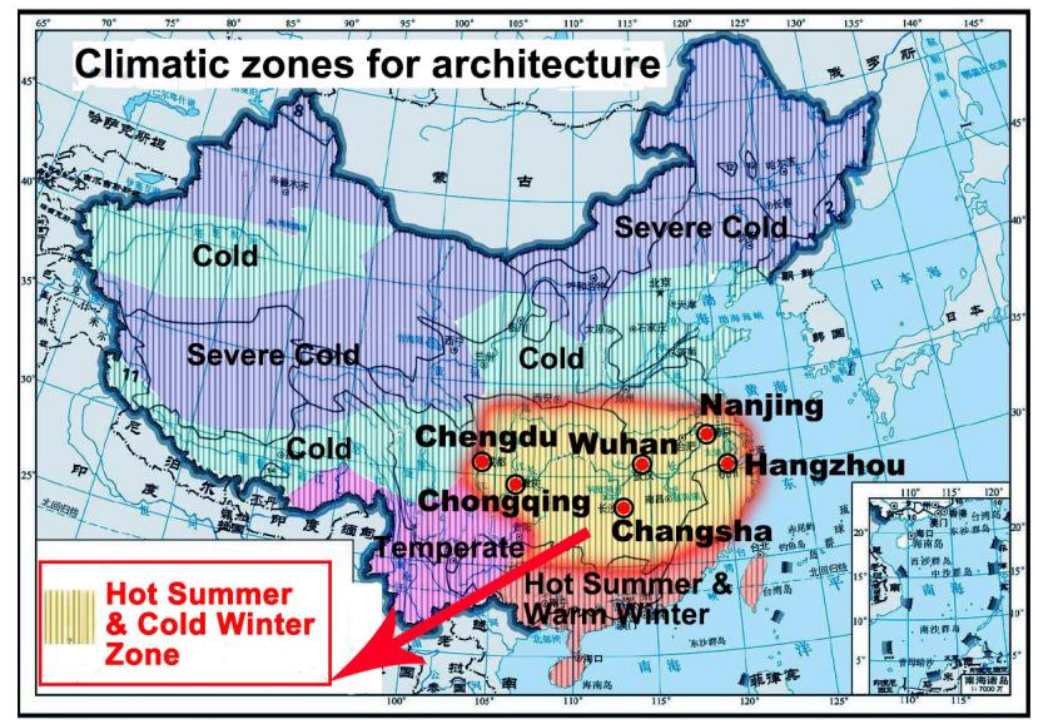

Figure 1: The six surveyed cities in the Hot Summer and Cold Winter zone of China

This paper presents the study of 505 residential buildings involving 11,524 subjects in the six cities located in the Hot Summer and Cold Winter zone covering Chongqing, Chengdu, Wuhan, Nanjing, Hangzhou and Changsha as illustrated in Figure 1.

\subsection{Subjective questionnaire}

The questionnaire was written in Chinese, and designed to obtain comprehensive information on human responses to the thermal environment. Subjects' thermal sensation vote uses the ASHRAE seven-point thermal sensation scale $(-3$ cold, -2 cool, -1 slightly cool, 0 neutral, +1 slightly warm, +2 warm, +3 hot). 
Occupants' clothing insulation uses the clo-checklist method, which was explained clearly in the questionnaire. Occupants can check their own types of clothing ensembles according to a list of clothes types provided in the Chinese code 'GB/T50785-2012: Appendix C: Clothing Insulation'[35], which was translated from 'ISO7730: Annex C: Estimation of thermal insulation of clothing ensembles' [36]. The values of different clothes types' insulation were obtained according to this code. Meanwhile, the status of windows (opened/closed) and fans (used/not used) was recorded during the survey.

\subsection{Environmental parameters measurements}

Indoor and outdoor environmental parameters including air temperature, relative humidity and air velocity were simultaneously measured during the survey. Because there were no obvious sources of heat radiation indoors, the indoor black globe temperature was not measured and assumed to equal the indoor air temperature in this study. Table 1 shows the instruments used to measure these environmental parameters, their accuracy and measuring ranges. According to ASHRAE 55 [37], the indoor measurement point was located at the height of the occupants' abdomen, i.e. at $0.6 \mathrm{~m}$ level above the floor for the seated occupants and $1.1 \mathrm{~m}$ level above the floor for the standing occupants respectively. The outdoor measurement points were placed in an open area near the buildings at the height of $1.1 \mathrm{~m}$.

Table 1: Instruments information.

\begin{tabular}{|c|c|c|c|c|}
\hline Description & Trade name & Parameters measured & Range & Accuracy \\
\hline Digital temperature-humidity & dwyer485 & Air temperature & $-30 \sim 85^{\circ} \mathrm{C}$ & $\pm 0.5^{\circ} \mathrm{C}$ \\
\hline instrument & & Relative humidity & $0 \sim 100 \%$ & $\pm 2 \%$ \\
\hline Hot-wire anemometer & Testo425 & Air velocity & $0 \sim 20 \mathrm{~m} / \mathrm{s}$ & $\pm(0.03 \mathrm{~m} / \mathrm{s}+5 \%$ measured value $)$ \\
\hline
\end{tabular}

\subsection{Buildings}

Among the buildings accommodating the apartments involved in the survey, most of them are 
located in downtowns of which $32.3 \%$ are along a main street and $54.7 \%$ are located inside residential communities, and other $13.0 \%$ are located in the suburbs. $60.1 \%$ of the surveyed buildings are reinforced concrete structures and the others are brick-concrete structures. Most buildings were less than 30 years old at the time of the survey. The buildings surveyed had one-, two-, three- and fourbedroom apartments usually with one dining and one living room. The average area of a room within the apartment was about $22.64 \mathrm{~m}^{2}$; all the surveyed rooms have operable outside windows.

\subsection{Subjects}

The subjects were $47.4 \%$ male and $52.6 \%$ female, and mostly aged between 20 and 60 . More than $95 \%$ of subjects weighed between 40 and $80 \mathrm{~kg}$, and most of their heights were between 150 and $180 \mathrm{~cm}$. Most of them had lived in the surveyed cities for between 8 and 42 years. The daily occupancy time in the apartment was mostly between 6 and 17 hours.

\section{Results Analysis}

\subsection{Thermal environments}

The monthly thermal environment parameters including air temperature, relative humidity and air velocity all around the year are illustrated in Figure 2. The twelve months in a year are traditionally divided into four seasons: winter (including December, January and February), spring (including March, April and May), summer (including June, July and August) and autumn (including September, October and November). The environmental parameters of the survey are summarized in Table 2. It can be seen that the minimum and maximum outdoor air temperatures are $-4.00^{\circ} \mathrm{C}$ and $41.50^{\circ} \mathrm{C}$ respectively, and the corresponding indoor air temperatures fluctuate from $1.50^{\circ} \mathrm{C}$ to $38.70^{\circ} \mathrm{C}$. The yearly mean outdoor and indoor air temperatures are $19.76^{\circ} \mathrm{C}$ and $20.50^{\circ} \mathrm{C}$ respectively. Most of the time in winter, the air temperature is lower than the yearly mean value, whereas most of the time in summer the air temperature is higher than the yearly mean value. 
Table 2: Summary of the seasonal variations in thermal environmental parameters

\begin{tabular}{|c|c|c|c|c|c|c|c|}
\hline \multicolumn{2}{|c|}{ Parameters } & \multirow{2}{*}{$\begin{array}{r}\begin{array}{r}\mathrm{T}_{\text {out }} \\
\left({ }^{\circ} \mathrm{C}\right)\end{array} \\
\mathbf{9 . 5 7}\end{array}$} & \multirow{2}{*}{$\begin{array}{r}\mathrm{T}_{\mathrm{a}} \\
\left({ }^{\circ} \mathrm{C}\right)\end{array}$} & \multirow{2}{*}{$\begin{array}{r}\begin{array}{r}\mathrm{RH}_{\text {out }} \\
(\%)\end{array} \\
\mathbf{5 9 . 1 1}\end{array}$} & \multirow{2}{*}{$\begin{array}{r}\mathrm{RH}_{\mathrm{a}} \\
(\%) \\
\mathbf{6 0 . 8 6}\end{array}$} & \multirow{2}{*}{$\begin{array}{r}\begin{array}{r}V_{\text {out }} \\
(\mathrm{m} / \mathrm{s})\end{array} \\
\mathbf{0 . 9 3}\end{array}$} & \multirow{2}{*}{$\begin{array}{r}\begin{array}{r}V_{a} \\
(\mathrm{~m} / \mathrm{s})\end{array} \\
\mathbf{0 . 0 9}\end{array}$} \\
\hline Winter & Mean & & & & & & \\
\hline \multirow{3}{*}{$(\mathrm{N}=2652)$} & Min. & -4.00 & 2.00 & 10.00 & 24.20 & 0.00 & 0.00 \\
\hline & Max. & 22.00 & 25.50 & 99.90 & 97.60 & 4.83 & 2.00 \\
\hline & SD & 4.21 & 3.37 & 18.40 & 14.20 & 0.96 & 0.18 \\
\hline \multirow{2}{*}{ Spring } & Mean & 20.05 & 20.42 & 65.59 & 66.87 & 1.16 & 0.17 \\
\hline & Min. & 2.00 & 5.00 & 20.00 & 22.30 & 0.00 & 0.00 \\
\hline \multirow[t]{2}{*}{$(\mathrm{N}=2965)$} & Max. & 36.60 & 34.20 & 99.00 & 97.00 & 6.70 & 1.91 \\
\hline & SD & 5.92 & 4.86 & 17.83 & 14.91 & 1.11 & 0.31 \\
\hline \multirow{2}{*}{ Summer } & Mean & 29.57 & 28.98 & 70.35 & 70.79 & 0.97 & 0.28 \\
\hline & Min. & 18.20 & 15.90 & 38.00 & 41.60 & 0.00 & 0.00 \\
\hline \multirow[t]{2}{*}{$(\mathrm{N}=2521)$} & Max. & 41.50 & 38.70 & 98.40 & 98.00 & 5.56 & 4.42 \\
\hline & SD & 3.58 & 2.86 & 11.31 & 9.90 & 1.03 & 0.41 \\
\hline \multirow{2}{*}{ Autumn } & Mean & 20.31 & 21.07 & 66.37 & 67.12 & 0.94 & 0.23 \\
\hline & Min. & 1.70 & 1.50 & 30.00 & 32.60 & 0.00 & 0.00 \\
\hline \multirow[t]{2}{*}{$(\mathrm{N}=3385)$} & Max. & 34.00 & 33.70 & 99.10 & 98.50 & 5.91 & 3.00 \\
\hline & SD & 6.61 & 5.99 & 14.15 & 12.95 & 1.16 & 0.42 \\
\hline \multirow{2}{*}{ Yearly } & Mean & 19.76 & 20.50 & 65.35 & 66.42 & 1.00 & 0.20 \\
\hline & Min. & -4.00 & 1.50 & 10.00 & 22.30 & 0.00 & 0.00 \\
\hline \multirow[t]{2}{*}{$(\mathrm{N}=11523)$} & Max. & 41.50 & 38.70 & 99.90 & 98.50 & 6.70 & 4.42 \\
\hline & SD & 8.59 & 7.37 & 16.17 & 13.63 & 1.08 & 0.35 \\
\hline
\end{tabular}

Due to the high frequency of rain in the region, the seasonal mean outdoor/indoor relative humidity is relatively high and ranges from $59.11 \%$ to $70.79 \%$ in different seasons. The seasonal mean indoor relative humidity is close to the outdoor value, and it is slightly higher in summer than that in winter. Throughout the year, the mean outdoor air velocity in different seasons is in the range of $0.93 \mathrm{~m} / \mathrm{s}$ to $1.16 \mathrm{~m} / \mathrm{s}$. The mean indoor air velocity in winter $(0.09 \mathrm{~m} / \mathrm{s})$ is obviously lower than that in spring $(0.17 \mathrm{~m} / \mathrm{s})$, autumn $(0.23 \mathrm{~m} / \mathrm{s})$ and summer $(0.28 \mathrm{~m} / \mathrm{s})$. It is revealed that there is a positive linear correlation between indoor air velocity and the indoor air temperature bins for the whole year, which can be expressed as:

$$
\mathrm{V}_{\mathrm{a}}=0.0088 \mathrm{~T}_{\mathrm{a}}+0.0122 \quad \mathrm{R}^{2}=0.70
$$

For the purpose of analysis of seasonal variation, a year is divided into two groups: Monthly Temperature Up (MTU) and Monthly Temperature Down (MTD) periods. The MTU is the months that the monthly average temperature is higher than the one of the previous month and vice versa, the MTD is lower, as seen in Figure 2. From the figure we can see that the MTU covers the months between 
February and July; the MTD between August and January in the next year. In the MTU, it is gradually getting warmer and hotter, while in the MTD it is getting cooler and colder.
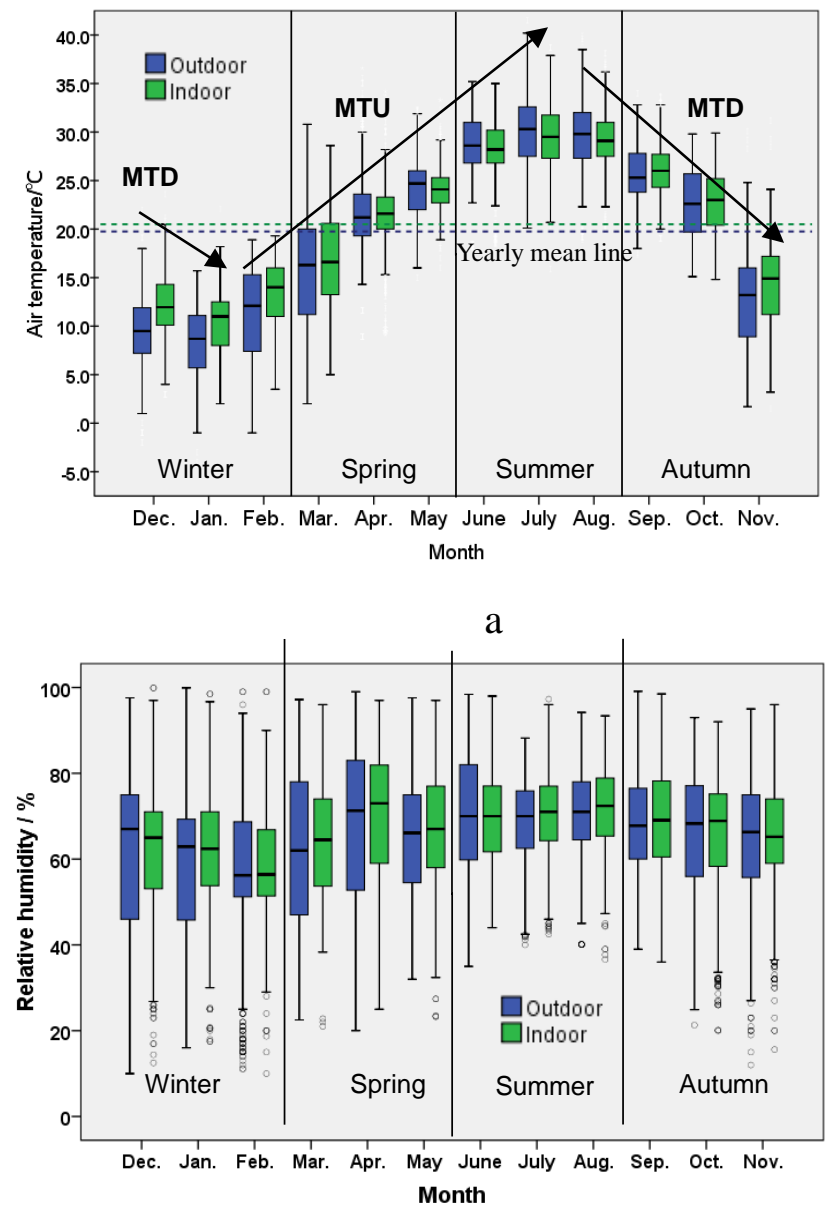

b

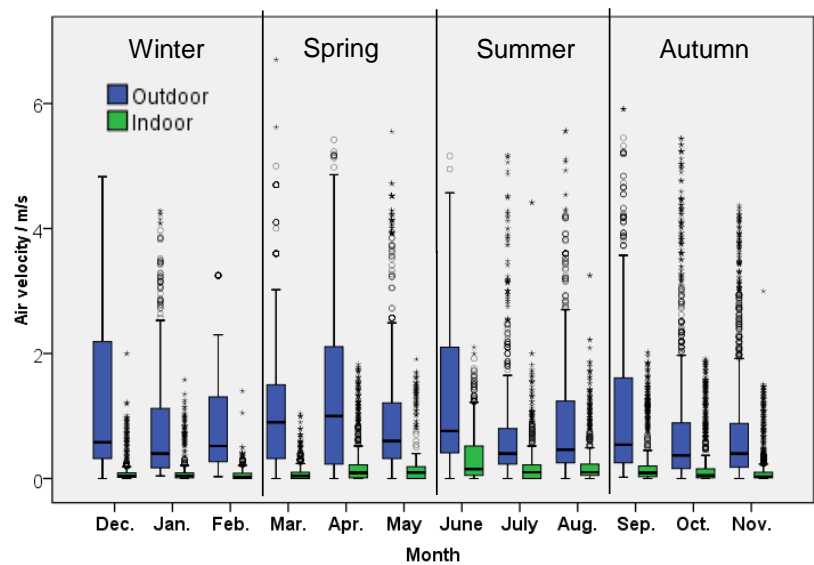

$\mathrm{c}$

Figure 2: Monthly variations of thermal environment: a) air temperature (two dash lines indicate yearly mean indoor/outdoor air temperature); b) relative humidity; c) air velocity 


\subsection{Behavioral responses}

\subsubsection{Definition}

The clothing insulation $\left(\mathrm{I}_{\mathrm{cl}}\right)$ is calculated by the clo-checklist method, as Section 2.2 describes. Proportion of fan use (PFU) is defined as the ratio of the number of fans being used to the total number being surveyed at one environmental parameter bin (or time period, e.g. a month, the same in the following), which reflects the possibility of fans being used at a certain environmental parameter (or time period). Proportion of windows opened (PWO) is defined as the ratio of the number of rooms with windows open to the total surveyed number of rooms at one environmental parameter bin (or time period).

\subsubsection{Monthly variations}

In this section, behavioral responses are analyzed in each single month. Occupants respond to environment variously in different months, as shown in Figure 3. Fan is mostly used in summer and shows different pattern in transition season, i.e. people use fan more in autumn than in spring because of thermal experience. The change of monthly clothing insulation and PWO with monthly mean air temperature (Figure 2a) are generally negative correlated and positive correlated respectively. Their values are stabilized in summer and winter, while change rapidly in transition season. PWO shows a lag behind monthly air temperature change in autumn, as it does not drop until November when air temperature starts to decrease after September (Figure2a). 


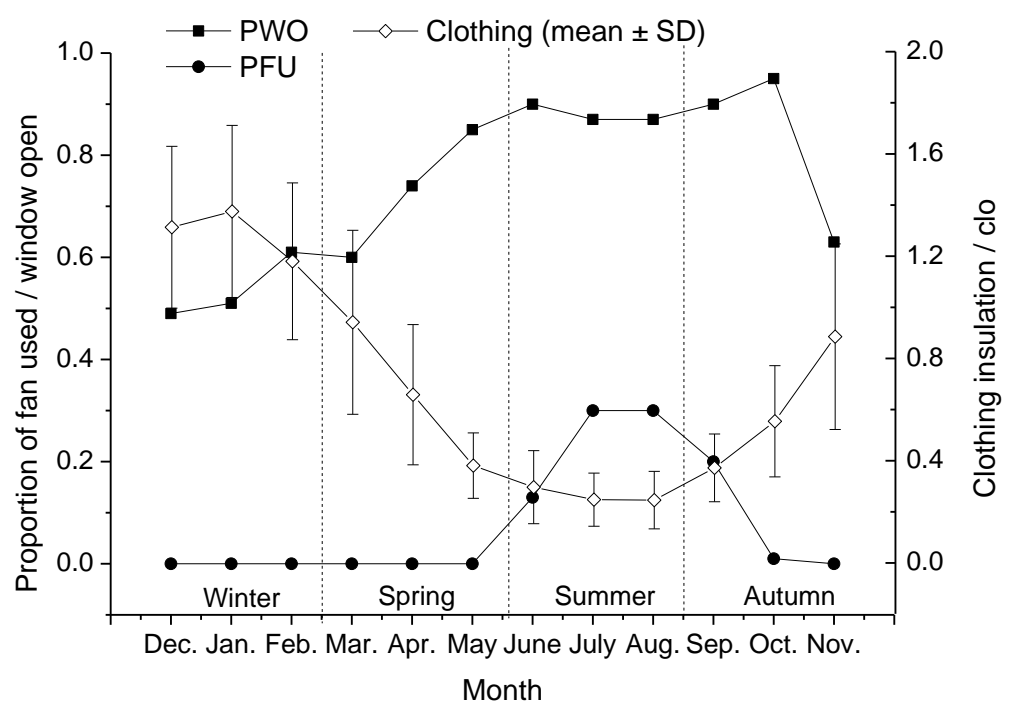

Figure 3: Monthly behavioral responses in whole year

\subsubsection{Relationship with thermal environment}

Air temperature bins are created for every $1^{\circ} \mathrm{C}$ interval, relative humidity bins are created for every $1 \%$ interval, and air velocity bins are created for every $0.05 \mathrm{~m} / \mathrm{s}$ interval. Those environmental parameter bins which contain a very small quantity of samples are not used for analysis.

Firstly, Spearman test is applied to see if there is a relationship between thermal environmental parameter bins and behavioral responses in whole year. Then the thermal environmental parameters with a significant and strong relationship $\left(\mathrm{r}_{\mathrm{s}}>0.3\right.$ or $\left.\mathrm{r}_{\mathrm{s}}<-0.3\right)$ are further described or statistically tested. As Table 3 shows, only the indoor and outdoor air temperature meet the correlation conditions.

Table 3: Spearman-rho (i.e. $r_{\mathrm{s}}$ ) rank correlation coefficient between environmental parameters and behavioral

\begin{tabular}{ccccccc}
\hline \multicolumn{7}{c}{ responses } \\
\hline $\mathrm{I}_{\mathrm{cl}}$ & $-0.797^{*}$ & $-0.813^{*}$ & $-0.114^{*}$ & $-0.141^{*}$ & 0.019 & $-0.173^{*}$ \\
$\mathrm{PFU}$ & $0.330^{*}$ & $\left.0.342^{*} \mathrm{C}\right)$ & $0.077^{*}$ & $0.095^{*}$ & 0.027 & $0.206^{*}$ \\
$\mathrm{PWO}$ & $0.394^{*}$ & $0.372^{*}$ & $-0.061^{*}$ & $-0.096^{*}$ & -0.018 & $0.208^{*}$ \\
\hline
\end{tabular}

$* \mathrm{p}<0.001$

To statistically test the correlations between environmental parameter bins and PFO or PWO respectively, logistic regression is used. Logistic regression is a useful method to analyze binary response variables with only two outcomes whose probability varies with a stimulus $[38,39]$. Efron's pseudo $\mathrm{R}^{2}$ is applied to evaluate the goodness-of-fit of logistic model in this study, and the level of significance is set at sig. $<0.01$. 


\subsubsection{Seasonal characteristics with air temperature}

Since air temperature is the most significant driver for the behavioral responses, more detail of the analysis about the regression equations and seasonal variations are described in this section.

\subsubsection{Clothing adaptation}

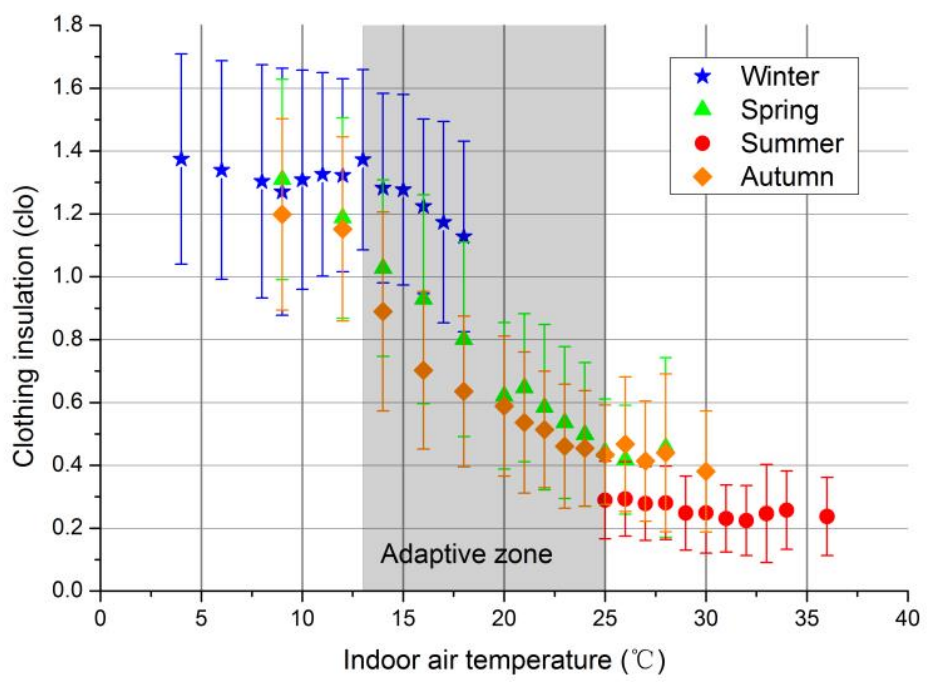

Figure 4: Seasonal variations of clothing insulation (mean value $\pm \mathrm{SD}$ ) with indoor air temperature

The clothing insulation variations with indoor air temperature in the four seasons are shown in Figure . The mean values of clothing insulation in winter, spring, autumn and summer are 1.30 clo, 0.69 clo, 0.60 clo and 0.26 clo, respectively. When the thermal conditions gradually become warmer, occupants adjust to lighter clothing patterns, especially in the adaptive zone (between $13^{\circ} \mathrm{C}$ and $25^{\circ} \mathrm{C}$ ) as depicted in the figure. However, clothing adaptations reach "limitation point" in summer (higher than $25^{\circ} \mathrm{C}$ ) and winter (below $13^{\circ} \mathrm{C}$ ). Beyond this "limitation point" even though the temperature increases/decreases, clothing insulation remains almost the same, which is consistent with other studies $[8,12,13,26,40]$. The seasonal variation of clothing insulation at the same temperature is also revealed in Figure 4.

\subsubsection{Utilization of fans}

The PFU with indoor air temperature in different seasons are shown in Figure . In winter and spring, the PFU is nearly zero. In autumn, the PFU is around 0.1 when the temperature is higher than $20^{\circ} \mathrm{C}$. In summer, the PFU has a strong correlation with indoor air temperature changing from 0 to 0.7 
when the indoor air temperature varies from $25^{\circ} \mathrm{C}$ to $36^{\circ} \mathrm{C}$

Logistic regression is used to fit the PFU with the indoor air temperature. The PFU for a whole year in this study can be expressed as:

$$
\mathrm{PFU}=\frac{e^{-11.354+0.343 * T_{a}}}{1+e^{-11.354+0.343 * T a}}
$$

The pseudo $\mathrm{R}^{2}$ is 0.98 , which means the degree of fit is good.

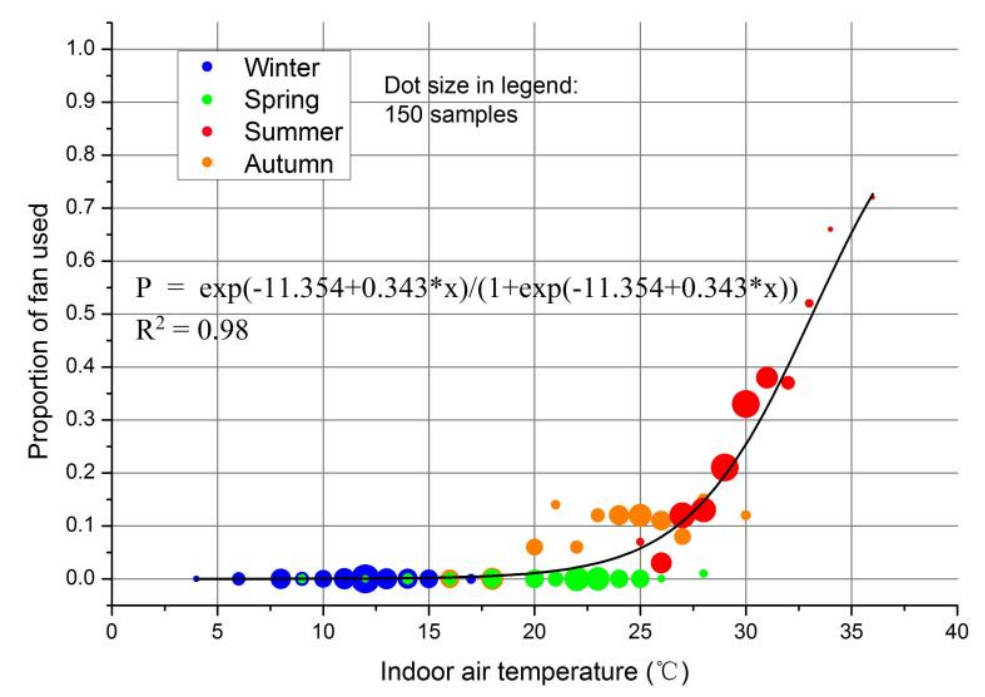

Figure 5: Proportion of fan use with indoor air temperature (width of dot - sample size, black solid curve -

regression curve of whole-year data, equation in the graph - expression of the regression curve and the following bubble graph are the same)

\subsubsection{Proportion of windows opened}

Figure 6 shows the relationship of the PWO and the outdoor air temperature. The PWO rises from about 0.3 to 0.8 when the outside temperature increased from $2^{\circ} \mathrm{C}$ to $17^{\circ} \mathrm{C}$ in winter. However, it fluctuates within the range of $0.8-1.0$ in summer, which does not change significantly according to the outside temperature. Also, the PWO is generally higher in autumn than that in spring.

Logistic regression is used to fit the PWO with the outdoor air temperature for the whole year, which is expressed as:

$$
\mathrm{PWO}=\frac{e^{-1.255+0.133 * T_{o u t}}}{1+e^{-1.255+0.133 * T_{o u t}}}
$$


The pseudo $\mathrm{R}^{2}$ is 0.92 , which means that the fit is good.

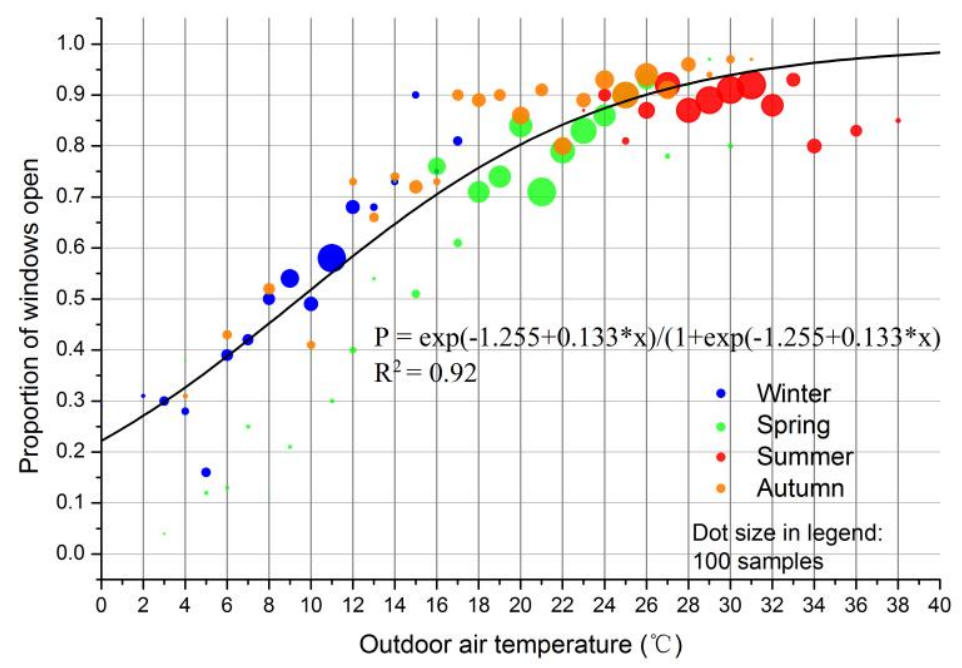

Figure 6: Proportion of windows opened with outside temperature

\subsection{Thermal comfort}

\subsubsection{Seasonal thermal sensation vote}

The thermal sensation vote (TSV) varied in different seasons, as shown in Figure 7. The linear regression of the TSV with the indoor air temperature for each season is listed in Table 4, and determination coefficient $\mathrm{R}^{2}$ is used to indicate the goodness of fit, which is above 0.90 in each season, meaning a strong goodness of fit.

Table 4: Regression equation of thermal sensation in different seasons

\begin{tabular}{cccc}
\hline Season & Regression equation & $\mathrm{R}^{2}$ & $\mathrm{~T}_{\mathrm{n}, \mathrm{s}}\left({ }^{\circ} \mathrm{C}\right)$ \\
\hline Winter & $\mathrm{TSV}=0.066 \mathrm{~T}_{\mathrm{a}}-1.39$ & 0.93 & 21.02 \\
Spring & $\mathrm{TSV}=0.057 \mathrm{~T}_{\mathrm{a}}-1.20$ & 0.95 & 21.11 \\
Summer & $\mathrm{TSV}=0.155 \mathrm{~T}_{\mathrm{a}}-3.76$ & 0.93 & 24.25 \\
Autumn & $\mathrm{TSV}=0.064 \mathrm{~T}_{\mathrm{a}}-1.52$ & 0.97 & 23.83 \\
\hline
\end{tabular}

$\mathrm{T}_{\mathrm{n}, \mathrm{s}}$ : Seasonal neutral temperature; $\mathrm{T}_{\mathrm{a}}$ : indoor air temperature.

The regressions can be used to quantify the thermal sensitivity responding to the indoor air temperature. The gradients of equations for winter, spring, summer and autumn are 0.066, 0.057, 0.155 and 0.064 respectively, which represent the rate of change of the thermal sensation with air temperature. 
The summer linear regression equation has the largest gradient indicating that occupants are more thermally sensitive to indoor air temperature variation in summer than in other seasons.

The neutral temperature is calculated when the TSV equals zero. This varies from season to season in the range of $21.02^{\circ} \mathrm{C}$ in winter to $24.25^{\circ} \mathrm{C}$ in summer, as shown in Figure 7 . The seasonal neutral temperatures are listed in Table 4 . We can see that the neutral temperature in summer is higher than that in winter, which is consistent with other research [12-20]. However, the neutral temperature in autumn is higher than that in spring though both seasons have similar outdoor/indoor average air temperatures, as shown in Table 2.

From Figure 7, differences in the thermal sensation between autumn and spring are observed, that is, occupants feel slightly cooler in autumn (represented by a diamond) than in spring (represented by a triangle) at the same temperature.

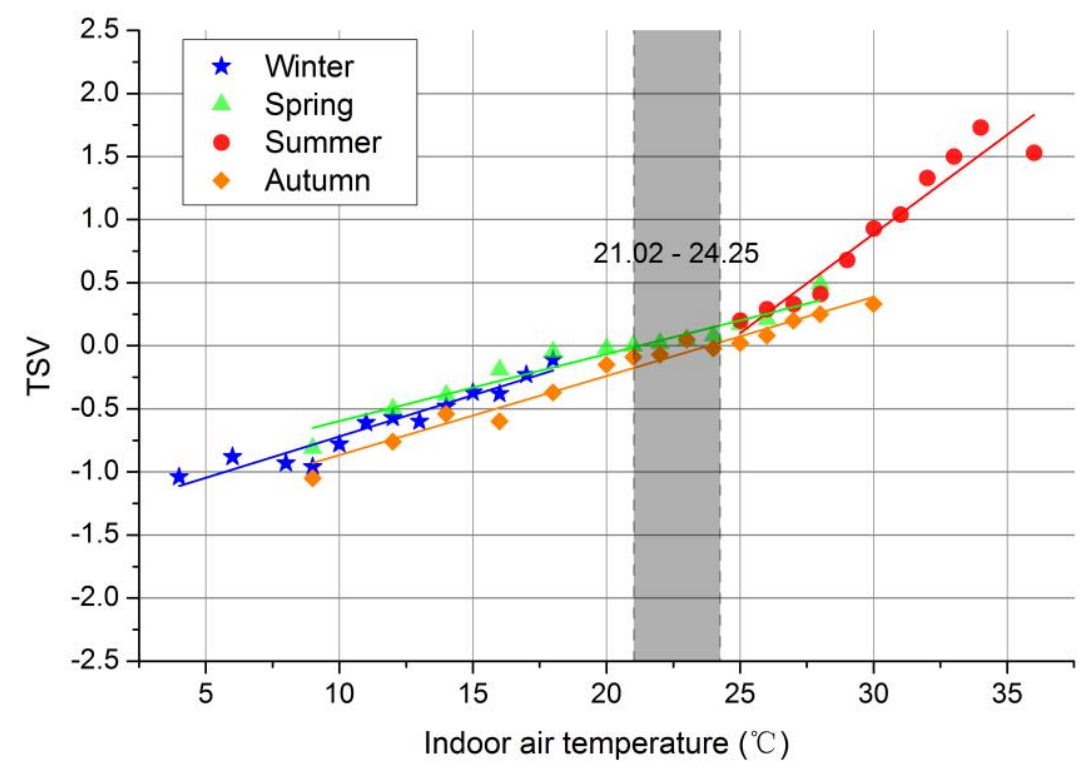

Figure 7: Seasonal variations of TSV with indoor air temperature

\subsubsection{Monthly neutral temperature}

By setting up the linear regression equation of TSV with indoor air temperature for a single month, the monthly neutral temperature is calculated when the TSV equals zero in this equation. Then the relationship between neutral temperature and outside temperature in the survey is obtained as follows:

$$
\mathrm{T}_{\mathrm{n}, \mathrm{m}}=0.153 \mathrm{~T}_{\text {out }, \mathrm{m}}+19.30 \quad \mathrm{R}^{2}=0.55
$$


The linear regression is plotted as the black dash line in Figure 8.

Obviously, in this study, the linear fit of monthly neutral temperature with monthly mean outdoor air temperature is not very strong $\left(\mathrm{R}^{2}=0.55\right)$, and overestimates the value in spring whilst underestimating the value in autumn (Figure 8). The monthly neutral temperatures have an obvious difference between MTD and MTU, which may be due to the lag of actual or perceptive control, different thermal experiences of previous months, and shifts in occupant expectations. The polynomial fit is shown as follows:

$$
\begin{array}{lll}
\text { MTD: } & \mathrm{T}_{\mathrm{n}, \mathrm{m}}=-0.0179 \mathrm{~T}_{\text {out }, \mathrm{m}^{2}+0.872 \mathrm{~T}_{\text {out }, \mathrm{m}}+13.89} & \mathrm{R}^{2}=0.80 \\
\text { MTU: } & \mathrm{T}_{\mathrm{n}, \mathrm{m}}=0.0077 \mathrm{~T}_{\text {out }, \mathrm{m}^{2}-0.161 \mathrm{~T}_{\text {out }, \mathrm{m}}+21.48} & \mathrm{R}^{2}=0.72
\end{array}
$$

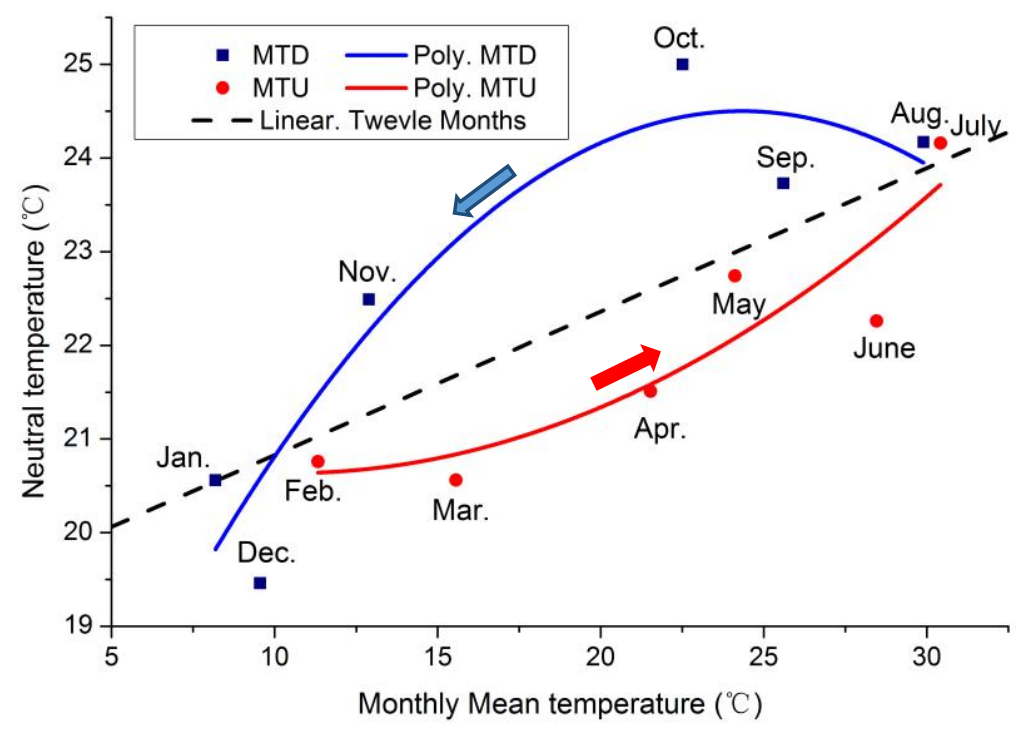

Figure 8: Monthly neutral temperature changes with the monthly mean outdoor air temperature (Note: MTD Monthly Temperature Down period; MTU - Monthly Temperature Up period.)

3.3.3 Daily neutral temperature with running-mean air temperature

According to Nicol and Humphreys [41], the neutral temperature is more important for a group of people on a particular day, rather than over the several days or weeks of the survey period, because the level of adaptation of the people has been changing on different days. The neutral temperature is calculated by the following equation:

$$
\mathrm{T}_{\mathrm{n}}=\mathrm{T}_{\mathrm{a}}+\mathrm{TSV} / \mathrm{G}
$$

Note: $\mathrm{G}$ is the Griffiths Constant, which is assumed to be $0.5 . \mathrm{T}_{\mathrm{a}}$ is the indoor air temperature, 
which is used as a measure of operative temperature in this study, since there were no obvious sources of heat radiation indoors in most conditions.

Using the data for the same day from the surveyed buildings in a city as a group, the daily neutral temperatures on each surveyed day is calculated by equation (7). To obtain the relationship between the daily neutral temperature $\left(\mathrm{T}_{\mathrm{n}, \mathrm{d}}\right)$ and outside climate considering thermal experience history, the running mean air temperature $\left(\mathrm{T}_{\mathrm{rm}}\right)$ method is applied, which is defined as:

$$
T_{\mathrm{rm}}=\lim _{n \rightarrow \infty} \frac{\sum_{i=1}^{n}\left(\alpha^{i-1} * T_{o d-i}\right)}{\sum_{i=1}^{n} \alpha^{i-1}}
$$

Where, $\alpha$ is a constant value $(<1$, appropriate to be 0.8$)$. $\mathrm{T}_{\text {od-i }}$ is the 24 -h daily mean temperatures for the previous days. In this case, previous daily mean temperatures in 30 days (i.e. $n=30$ ) are used to calculate the running mean air temperature.

Thus the relationship between neutral temperature and outside climate for the whole year is found as follows:

$$
\mathrm{T}_{\mathrm{n}, \mathrm{d}}=0.709 \mathrm{~T}_{\mathrm{rm}}+8.25 \quad \mathrm{R}^{2}=0.87
$$

This linear regression is plotted as the black dash line in Figure 9.

Using the same method as above, while the outcome of $\mathrm{T}_{\mathrm{n}, \mathrm{d}}$ and $\mathrm{T}_{\mathrm{rm}}$ was divided into four seasons (as defined in Section 3.1) based on their date, the seasonal variation of the relationship between $T_{n, d}$ and $\mathrm{T}_{\mathrm{rm}}$ is shown in Figure 9 and Table 5.

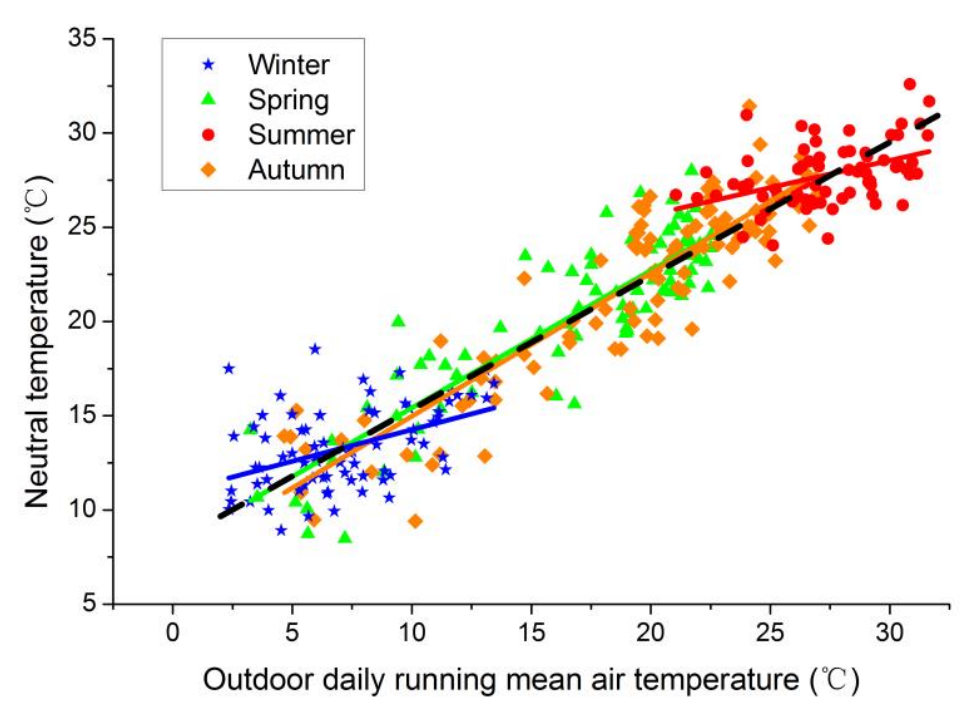


Figure 9: Daily neutral temperature with outdoor daily running mean air temperature (the black dash line whole year data, the colorful straight line - seasonal data)

Table 5: Regression equation of neutral temperature with running mean air temperature in different seasons

\begin{tabular}{cll}
\hline Season & Regression equation & $\mathrm{R}^{2}$ \\
\hline Winter & $\mathrm{T}_{\mathrm{n}, \mathrm{d}}=0.34 \mathrm{~T}_{\mathrm{rm}}-10.91$ & 0.19 \\
Spring & $\mathrm{T}_{\mathrm{n}, \mathrm{d}}=0.73 \mathrm{~T}_{\mathrm{rm}}-8.12$ & 0.77 \\
Summer & $\mathrm{T}_{\mathrm{n}, \mathrm{d}}=0.29 \mathrm{~T}_{\mathrm{rm}}-19.90$ & 0.18 \\
& & \\
Autumn & $\mathrm{T}_{\mathrm{n}, \mathrm{d}}=0.76 \mathrm{~T}_{\mathrm{rm}}-7.36$ & 0.81 \\
\hline & & \\
\hline
\end{tabular}

The daily neutral temperature shifted with outside climate mainly in transitional seasons. It can be seen that the daily neutral temperature has a strong correlation with the outdoor running mean air temperature in spring and autumn, and the regression lines show no significant difference between spring and autumn, which coincide with the whole-year regression line using this same method. Whereas, the relationship is very weak in summer and winter, implying the occupants' limitation of adaption during these seasons.

We can also find that the neutral temperature has a stronger relationship with the running mean outdoor air temperature than with the monthly mean outdoor air temperature over the whole year, which can be seen from the coefficient of determination $\mathrm{R}^{2}$ of Equation (4) compared with that from Equation (9) which are derived from these two different methods. It can be deduced that thermal experience history has a significant effect on occupants' thermal comfort.

\section{Discussions}

\subsection{Variation of thermal sensation between spring and autumn}

There is strong evidence that thermal sensations vary in different seasons. There are several possible reasons to explain the difference of thermal sensation between spring and autumn. The thermal environments in real buildings are dynamic ones (i.e. not steady-state). It is complex to predict occupants' thermal sensations by physical parameters in dynamic environments [42-46], especially 
considering their adaptation to the dynamic thermal environment in real buildings [47].

According to the adaptive comfort theory, if a change produces discomfort, people react in ways which tend to restore their comfort [48]. This can be generally categorized into three main paths: behavioral adjustment, physiological acclimatization, and psychological adaption [49].

Firstly, the behavioral patterns in the two transitional seasons are different and show a lag of behavioral response to the changing climate. People take actions after they feel uncomfortable, but they keep their previous state in mind. In this study, we find that occupants wore less clothing (Figure ), and the frequencies of 'proportion of windows opened and fan use' are higher in autumn than those in spring (Figure and Figure 6), which is closer to the former season. Due to the lower clothing insulation and higher indoor air velocity (Table 2), people feel cooler in autumn than they do in spring at the same indoor air temperature (Figure ), which also results in a higher neutral temperature in autumn (Table 4). Besides that, other behavioral responses, which are not analyzed in this study, can also affect thermal comfort. For example, a study [50] observed that people increased their physical activities in spring.

Secondly, the processes of thermal acclimatization operate in opposite ways in spring and autumn. Laboratory experiments $[51,52]$ found that for the same thermal condition, subjects' skin temperature, tympanic temperature, metabolic rate and body fat were higher in winter than they were in summer. After the cold acclimatization in winter, occupants are more sensitive to a warm environment in spring. And after the cold deacclimatization in summer, occupants become sensitive to cold, which can also cause a lower thermal sensation vote in autumn than in other seasons (Figure ).

Thirdly, psychological adaption including habituation, expectation, preference, and perceived control also play an important role in occupants' thermal responses to thermal environment change. A study [53] found that the psychological adaption can speed up the process of thermal adaption to the variations of the outdoor climate conditions. Another study [54] also revealed that occupants' expectations affect their ability of adapt to a non-neutral indoor climate. Some studies indicated that 
subjects with high perceived control tended to report more positive comfort perceptions [55, 56], and lack of perceived control reduced thermal comfort [57]. The unique culture and living habits of people in this region may also make the results of this study differ from other studies with different regions and people [48].

\subsection{Predicted thermal sensation by adaptive algorithms}

Fanger and Toftum [58] introduced an extended Predicted Mean Vote (PMV) model known as the ePMV to adjust the PMV model applicable in free-running buildings.

The expression for the ePMV model is as follows:

$$
e P M V=e \times P M V
$$

Where, $e$ is the expectancy factor, varying between 1 and 0.5 . For air-conditioned buildings, e equals 1 . For non-air-conditioned buildings, this factor is assumed to depend on the local climate and increasing usage of mechanical conditioning. As indicated above, in areas where the weather is warm only in summer, e is assumed to be 0.7-0.9.

Yao et al. [59] proposed an Adaptive Predicted Mean Vote (aPMV) and several technical measures for improving the indoor thermal comfort in buildings.

The expression for the aPMV model is as follows:

$$
a P M V=\frac{P M V}{1+\lambda P M V}
$$

Where, $\lambda$ is the adaptive coefficient for warm and cool conditions to account for factors such as climate; culture; social; and physiological, psychological, and behavioral adaption.

This model was applied to the current Chinese National Standard 'Evaluation Standard for Indoor Thermal Environments in Civil Buildings GB/T50785-2012' [35]. The value of the adaptive coefficient $\lambda$ for residential buildings in the HSCW zone is given by GB/T50785-2012 as follows: $\lambda=0.21$ for warm conditions, $\lambda=-0.49$ for cool conditions. 

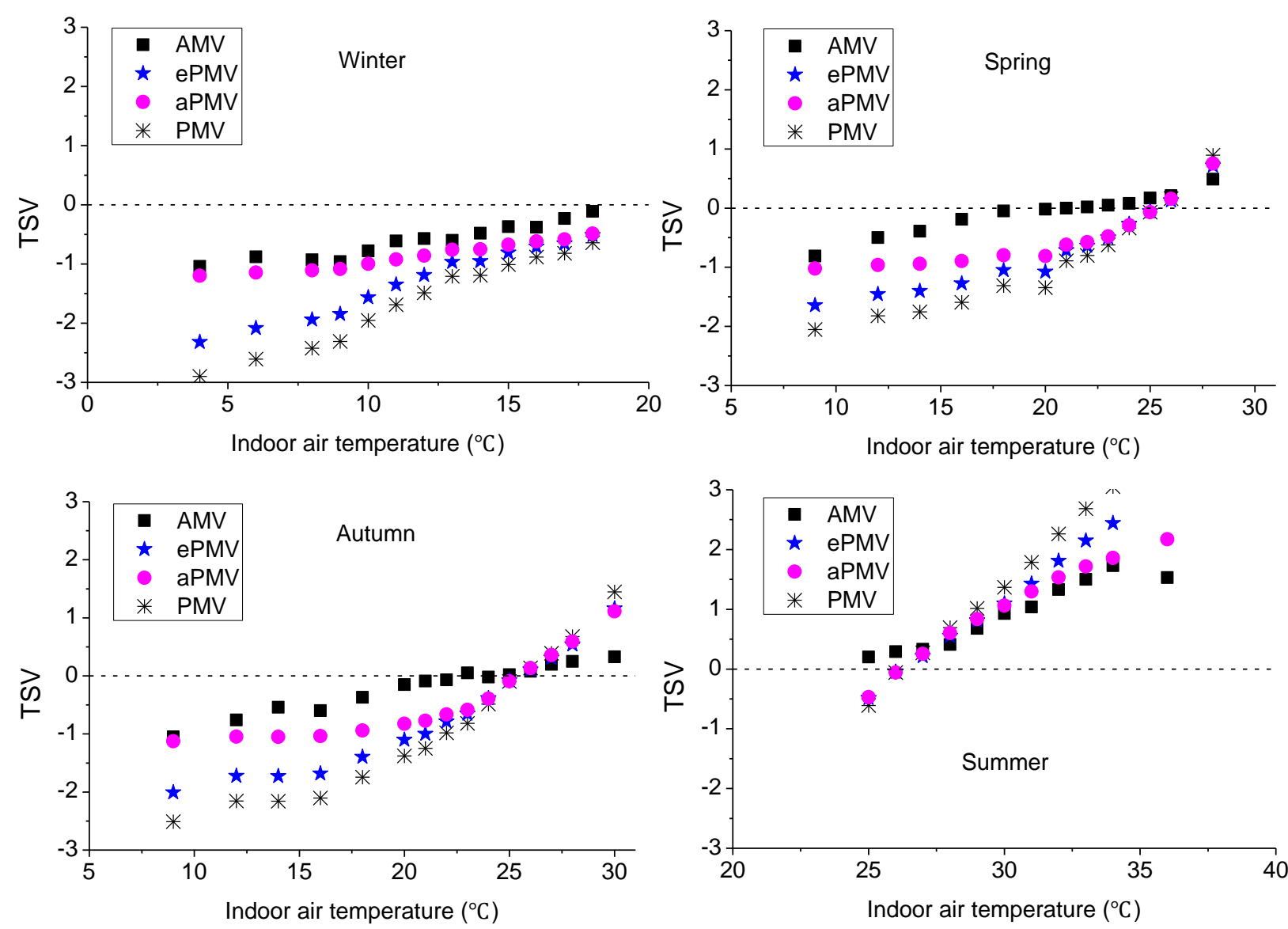

Figure 10: Comparison of thermal sensation models for different seasons

Note: AMV - actual mean vote of thermal sensation; $\mathrm{e}=0.8(\mathrm{ePMV}) ; \lambda=0.21$ when $\mathrm{PMV} \geq 0, \lambda=-0.49$, when PMV $<0(\mathrm{aPMV})$.

The thermal sensation vote predicted by aPMV, ePMV and PMV models are compared with the actual mean vote of thermal sensation (AMV) which is equal to the TSV value (in Section 3.3.1) from the survey of this study. As Figure 10 shows, the thermal sensation vote is better predicted by the aPMV and ePMV models than by the PMV model. The predicted value of the aPMV model is more accurate than the ePMV model, implying that $\mathrm{e}=0.8$ is not the suitable value for free-running residential buildings in the HSCW zone of China. For warm conditions in summer and cool conditions in winter, the aPMV model performed quite well using the value of $\lambda$ provided in GB/T50785-2012, which is recommended for thermal comfort evaluation in residential buildings in this region. 


\section{Conclusions}

This paper presents research into thermal sensation variation according to the changing of seasons based on the data collected in 505 free-running mode residential buildings involving 11,524 subjects in six cities in the HSCW Zone in China. A significant difference of human thermal adaption at different seasons has been demonstrated. The main conclusions are drawn as follows:

(1) Behavioral responses show variety in different seasons.

- Air temperature is found to be the most significant driver to occupants' thermal adaption behaviors in the whole year. And a lag of behavioral responses behind climate change in transitional seasons is observed.

- Occupants adjust their clothing insulation according to ambient temperature mainly in transitional seasons when temperature is between $13^{\circ} \mathrm{C}$ and $25^{\circ} \mathrm{C}$.

- Occupants also take actively response to control the indoor air velocity: a highest proportion of windows are closed in winter when outside temperature is low, and occupants rely on using fans more when the temperature is above $25^{\circ} \mathrm{C}$ in summer. These adaptive behaviors result in the highest indoor air velocity recorded during the survey in summer and the lowest in winter.

(2) Significance of seasonal variations of thermal sensations and neutral temperatures have been revealed.

- The seasonal neutral temperatures in summer and winter are $24.25^{\circ} \mathrm{C}$ and $21.02^{\circ} \mathrm{C}$ respectively in HSCW zone of China. However, the seasonal neutral temperature in autumn is higher than that in spring $\left(23.83^{\circ} \mathrm{C}\right.$ and $21.11^{\circ} \mathrm{C}$ respectively), although the outside and indoor temperatures are similar in autumn and spring.

- The lag of behavioral response to seasonal climate change is also observed, which amplifies the thermal sensation difference between spring and autumn. Due to the higher proportion of fan usage and windows opened, indoor air velocity is generally higher in autumn than that in spring, and the clothing insulation is generally lower. Occupants feel cooler at the same 
temperature in autumn, resulting in a higher neutral temperature in autumn than that in spring.

(3) The dynamic evaluation of the thermal comfort temperature is strongly recommended for residential buildings.

- When predicting the comfort temperature using the monthly mean outdoor temperature method, the degree of prediction accuracy will be better when the time period is divided into Monthly Temperature Down (MTD) and Monthly Temperature Up (MTU) periods.

- Using the running mean outdoor temperature is better than the monthly mean temperature for the prediction of the comfort temperature considering the effect of thermal experience history in transitional seasons.

- There is a good agreement of the aPMV prediction results with the values of the AMV from the survey. Therefore, the aPMV suggested in the GB/T50785-2012 model is suitable for making predictions of thermal sensations in free-running residential buildings in the HSCW Zone of China.

\section{Acknowledgement}

The authors would like to thank the Natural Science Foundation of China (NSFC 51561135002) and the International Science \& Technology Cooperation Program of China (No.2014DFA62970), and the Graduate Scientific Research and Innovation Foundation of Chongqing, China (No. CYS16006), and the 111 Project (No.B13041) for their financial support.

\section{References}

[1] Tsinghua University Building Energy Research Centre (TUBERC): 2014 Annual Report on China Building Efficiency, Architecture and Building Press, Beijing, 2014 [in Chinese].

[2] CMA Meteorological Information Centre: The Dedicated Meteorological Data Set for the Analysis of Building 
Thermal Environment in China, China Construction Industry Publish House, Beijing, 2005 [in Chinese].

[3] B. Li, R. Yao, Building energy efficiency for sustainable development in China: challenges and opportunities, Build. Res. Inf. 40 (4) (2012) 417-431.

[4] General Office of the State Council of the People's Republic of China: GBF (2014) No. 31, Circular of the General Office of the State Council Concerning Printing and Issuing the Action Plan (2014-2020) of Energy Development Strategy, 2014, [Online] (http://www.gov.cn/zhengce/content/2014-11/19/content_9222.htm) (accessed 2016-03-01).

[5] S.Asadi, M. Fakhari, M. Sendi, A study on the thermal behavior of traditional residential buildings: Rasoulian house case study, J. Build. Eng. 7 (2016) 334-342.

[6] Q.J. Kwong, N.M. Adam, B.B. Sahari, Thermal comfort assessment and potential for energy efficiency enhancement in modern tropical buildings: A review, Energy Build. 68 (2014) 547-557.

[7] M. Ozel, Effect of indoor design temperature on the heating and cooling transmission loads, J. Build. Eng. 7 (2016) 46-52.

[8] R. Yao, J. Liu, B. Li, Occupants' adaptive responses and perception of thermal environment in naturally conditioned university classrooms, Appl. Energy 87 (2010) 1015-1022.

[9] J. van Hoof, Forty years of Fanger's model of thermal comfort: comfort for all? Indoor Air 18 (2008) 182-201.

[10] A.K. Mishra, M. Ramgopal, Field studies on human thermal comfort - An overview, Build. Environ. 64 (2013) 94-106.

[11] R.F. Rupp, N.G. Vásquez, R. Lamberts, A review of human thermal comfort in the built environment, Energy Build. 105 (2015) 178-205.

[12] J.F. Nicol, I.A. Raja, A. Allaudin, G.N. Jamy, Climatic variations in comfortable temperatures: the Pakistan projects, Energy Build. 30 (1999) 261-279. 
[13] K. Cena, R.J. de Dear, Thermal comfort and behavioural strategies in office buildings located in a hot-arid climate, J. Therm. Biol. 26 (2001) 409-414.

[14] S. Heidari, S. Sharples, A comparative analysis of short-term and long-term thermal comfort surveys in Iran, Energy Build. 34 (2002) 607-614.

[15] K.W.H. Mui, W.T.D. Chan, Adaptive comfort temperature model of air-conditioned building in Hong Kong, Build. Environ. 38 (2003) 837-852

[16] W. Li, B. Li, M. Xu, S. Jing, Thermal comfort in naturally ventilated indoor environment in hot and humid climate zone in P.R. China, J. Cent. South Univ. Technol. 16 (s1) (2009) 33-37.

[17] H.B. Rijal, H. Yoshida, N. Umemiya, Seasonal and regional differences in neutral temperatures in Nepalese traditional vernacular houses, Build. Environ. 45 (2010) 2743-2753

[18] R.-L. Hwang, C.-P. Chen, Field study on behaviors and adaptation of elderly people and their thermal comfort requirements in residential environments, Indoor Air 20 (2010) 235-245

[19] B. Cao, Y. Zhu, Q. Ouyang, X. Zhou, L. Huang, Field study of human thermal comfort and thermal adaptability during the summer and winter in Beijing, Energy Build. 43 (2011) 1051-1056.

[20] H.-H. Liang, T.-P. Lin, R.-L. Hwang, Linking occupants' thermal perception and building thermal performance in naturally ventilated school buildings, Appl. Energy 94 (2012) 355-363.

[21] Chinese Standard GB 50178-93. Standard of Climatic Regionalization for Architecture, Standardization Administration of China (SAC), Beijing. 1993 [in Chinese].

[22] B. Li, M. Tan, H. Liu, X. Ma and W. Zhang, Occupant's Perception and Preference of Thermal Environment in Free-running Buildings in China, Indoor Built Environ. 19 (4) (2010) 405-412.

[23] B. Li, W. Yu, M. Liu, Climatic Strategies of Indoor Thermal Environment for Residential Buildings in Yangtze River Region, China. Indoor Built Environ. 20 (1) (2011) 101-111 
[24] H. Liu, W. Zheng, B. Li, M. Tan, Y. Gao, Z. Jing, Behavioural adaptation of indoor thermal environment in hotsummer and cold-winter zone, J. Cent. South Univ. 42 (6) (2011) 1805-1812 [in Chinese].

[25] J. Liu, R. Yao, J. Wang, B. Li, Occupants' behavioural adaptation in workplaces with non-central heating and cooling systems, Appl. Therm. Eng. 35 (2012) 40-54.

[26] W. Liu, Y. Zheng, Q. Deng, L.Yang, Human thermal adaptive behaviour in naturally ventilated offices for different outdoor air temperatures: A case study in Changsha China, Build. Environ. 50 (2012) 76-89.

[27] X.J. Ye, Z.P. Zhou, Z.W. Lian, H.M. Liu, C.Z. Li, Y.M. Liu, Field study of a thermal environment and adaptive model in Shanghai, Indoor Air 16 (2006) 320-326.

[28] W. Yang, G. Zhang, Thermal comfort in naturally ventilated and air-conditioned buildings in humid subtropical climate zone in China, Int. J. Biometeorology 52 (2008) 385-398.

[29] J. Han, G. Zhang, Q. Zhang, J. Zhang, J. Liu, L. Tian, C. Zheng, J. Hao, J. Lin, Y. Liu, D. J. Moschandreas, Field study on occupants' thermal comfort and residential thermal environment in a hot-humid climate of China, Build. Environ. 42 (2007) 4043-4050.

[30] X.L. Ji, W.Z. Lou, Z. Z. Dai, B.G. Wang, S.Y. Liu, Predicting thermal comfort in Shanghai's non-air-conditioned buildings, Build. Res. Inf. 34 (5) (2006) 507-514.

[31] H. Liu, Y. Wu, H. Zhang, X. Du, A field study on elderly people's adaptive thermal comfort evaluation in naturally ventilated residential buildings in summer, J. HVAC 45 (2015) 50-58 [in Chinese].

[32] M. Tan, B. Li, H. Liu, W. Zhang, W. Li, M. Xu, Field experiments on thermal comfort in university dormitories in Chongqing, China, J. Cent. South Univ. Technol. 16(s1) (2009) 55-61.

[33] J. Han, W. Yang, J. Zhou, G. Zhang, Q. Zhang, D. J. Moschandreas, A comparative analysis of urban and rural residential thermal comfort under natural ventilation environment, Energy Build. 41(2009)139-145.

[34] B. Li, R. Yao, Q. Wang, Y. Pan, An introduction to the Chinese Evaluation Standard for the indoor thermal 
environment, Energy Build. 82 (2014) 27-36.

[35] Chinese Standard GB/T50785-2012, Evaluation standard for indoor thermal environments in civil buildings, China Academy of Building Research and Chongqing University, Beijing, 2012 [in Chinese].

[36] ISO 7730:2005, Ergonomics of the thermal environment - Analytical determination and interpretation of thermal comfort using calculation of the PMV and PPD indices and local thermal comfort criteria, International Standardization Organization, Geneva, 2005.

[37] ANSI/ASHRAE Standard 55, Thermal Environmental Conditions for Human Occupancy, ASHRAE, Atlanta, 2013.

[38] R. Fritsch, A. Kohler, M. Nygardferguson, J.L. Scartezzini, A stochastic-model of user behavior regarding ventilation, Build. Environ. 25 (1990) 173-181.

[39] F. Haldi, D. Robinson, On the behaviour and adaptation of office occupants, Build. Environ. 43 (2008) 2163 2177

[40] P.M. de Carvalho, M.G. da Silva, J.E. Ramos, Influence of weather and indoor climate on clothing of occupants in naturally ventilated school buildings, Build. Environ. 59 (2013) 38-46.

[41] F. Nicol, M. Humphreys, Derivation of the adaptive equations for thermal comfort in free-running buildings in European standard EN15251, Build. Environ. 45 (2010) 11-17.

[42] Y. Yang, R. Yao, B. Li, H. Liu, L. Jiang, A method of evaluating the accuracy of human body thermoregulation models, Build. Environ. 87 (2015) 1-9.

[43] H. Liu, J. Liao, D. Yang, X. Du, P. Hu, Y. Yang, B. Li, The response of human thermal perception and skin temperature to step-change transient thermal environments, Build. Environ. 73 (2014) 232-238.

[44] X. Du, B. Li, H. Liu, D. Yang, W. Yu, J. Liao, Z. Huang, K. Xia, The Response of Human Thermal Sensation and Its Prediction to Temperature Step-Change (Cool-Neutral-Cool), Plos One, 9 (8) (2014). 
[45] K.C. Parsons, The effects of gender, acclimation state, the opportunity to adjust clothing and physical disability on requirements for thermal comfort, Energy Build. 34 (2002) 593-599.

[46] Y. Liu, L. Wang, J. Liu, Y. Di, A study of human skin and surface temperatures in stable and unstable thermal environments, J. Therm. Biol. 38 (2013) 440-448.

[47] Y. Zhu, Q. Ouyang, B. Cao, X. Zhou, J. Yu, Dynamic thermal environment and thermal comfort, Indoor Air 26 (2016) 125-137.

[48] J.F. Nicol, M.A. Humphreys, Adaptive thermal comfort and sustainable thermal standards for buildings, Energy Build. 34 (2002) 563-572.

[49] G.S. Brager, R.J. de Dear, Thermal adaptation in the built environment: a literature review, Energy Build. 27 (1998) 83-96.

[50] R.J. Shephard, Y. Aoyagi, Seasonal variations in physical activity and implications for human health, Eur. J. Appl. Physiol. 107 (2009) 251-271.

[51] N. Umemiya, Seasonal variations of physiological characteristics and thermal sensation under identical thermal conditions, J. Physiol. Anthrop. 25 (1) (2006) 29-39.

[52] T.M. Makinen, T. Paakkonen, L. A Palinkas. H. Rintamanki, J. Leppaluoto, J. Hassi, Seasonal changes in thermal responses of urban residents to cold exposure, Comp. Biochem. Physiol. A 139 (2004) 229-238

[53] W. Liu, H. Hao, J. Xiong, Q. Deng, Feedback effect of human physical and psychological adaption on time period of thermal adaption in naturally ventilated building, Build. Environ. 76 (2014) 1-9.

[54] M. Luo, R. de Dear, W. Ji, B. Lin, Q. Ouyang, Y. Zhu, The dynamics of thermal comfort expectations: The problem, challenge and impication, Build. Environ. 95 (2016) 322-329.

[55] G.Y. Yun, K. Steemers, N. Baker, Natural ventilation in practice: linking facade design, thermal performance, occupant perception and control, Build. Res. Inf. 36 (6) (2008) 608-624. 
[56] M. Luo, B. Cao, W. Ji, Q. Ouyang, B. Lin, Y. Zhu, The underlying linkage between personal control and thermal comfort: Psychological or physical effects? Energy Build. 111 (2016) 56-63.

[57] S. Natarajan, J. Rodriguez, M. Vellei, A field study of indoor thermal comfort in the subtropical highland climate of Bogota, Colombia, J. Build. Eng. 4 (2015) 237-246.

[58] P.O. Fanger, J. Toftum, Extension of the PMV model to non-air-conditioned buildings in warm climates, Energy Build. 34 (2002) 533-536.

[59] R. Yao, B. Li, J. Liu, A theoretical adaptive model of thermal comfort - Adaptive Predicted Mean Vote (aPMV), Build Environ. 44 (2009) 2089-2096. 